\title{
Dietary diversity score and cardiovascular risk factors in Tehranian adults
}

\author{
Leila Azadbakht, Parvin Mirmiran, Ahmad Esmaillzadeh and Fereidoun Azizi* \\ Endocrine Research Center, Shaheed Beheshti University of Medical Sciences, PO Box 19395-4763, \\ Tehran, Islamic Republic of Iran
}

Submitted 2 June 2005: Accepted 26 October 2005

\begin{abstract}
Aim: To evaluate the relationship between dietary diversity score (DDS) and cardiovascular risk factors in Tehranian adults.

Methods: In this population-based cross-sectional study, a representative sample of 581 subjects ( 295 males and 286 females) aged over 18 years, residents of Tehran, participated. Hypercholesterolaemia, hypertriglyceridaemia and low high-density lipoprotein cholesterol were defined according to the Adult Treatment Panel III guidelines of the National Cholesterol Education Program. Diabetes was defined as fasting plasma glucose concentration $\geq 126 \mathrm{mg} \mathrm{dl}^{-1}$ or 2 -h post challenge glucose concentration $\geq 200 \mathrm{mg} \mathrm{dl}^{-1}$. Hypertension was defined on the basis of the sixth report of the Joint National Committee on Prevention, Detection, Evaluation and Treatment of High Blood Pressure. Dietary diversity was defined according to the Diet Quality Index revised.

Results: Mean ( \pm standard deviation) DDS was $6.15 \pm 1.02$. The probability of having diabetes (odds ratio (OR) among quartiles: 1.45, 1.26, 1.11 and 1.00, respectively; $P$ for trend $=0.04)$ and hypertriglyceridaemia $(\mathrm{OR}=1.41,1.23,1.05$ and 1.00, respectively; $P$ for trend $=0.04$ ) decreased with increasing quartile of the diversity score for whole grains. The probability of having obesity (OR among quartiles: 1.39, 1.06, 1.03 and 1.00 , respectively; $P$ for trend $=0.03$ ), hypercholesterolaemia $(\mathrm{OR}=1.46,1.28,1.11$ and 1.00 , respectively; $P$ for trend $=0.03)$, hypertension $(\mathrm{OR}=1.32,1.17,1.13$ and 1.00 , respectively; $P$ for trend $=0.03)$ and high low-density lipoprotein cholesterol (LDL-C) $(\mathrm{OR}=1.25,1.12,1.07$ and 1.00 , respectively; $P$ for trend $=0.04$ ) decreased with increasing quartile of the diversity score for vegetables. The probability of having hypercholesterolaemia, high LDL-C, hypertension and diabetes decreased with quartile of the DDS. But the probability of being obese increased with quartile of the DDS ( $P$ for trend $=0.03$ ).

Conclusion: DDS was inversely associated with cardiovascular risk factors in this cross-sectional study. Increased diversity scores of diets, to increase the variety score for vegetables, may be emphasised in programmes attempting to bring about changes in lifestyle.
\end{abstract}

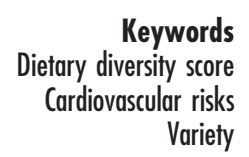

In contrast to trends observed in northern Europe and the $\mathrm{USA}^{1}$, recent data show that mortality from cardiovascular diseases (CVD) is increasing in Iran $^{2}$. Further progress in prevention may depend on identifying the population at increased risk for CVD. Previous studies in this population showed that $22 \%$ of men and $24 \%$ of women aged 20 years and above had hypertension. Fourteen per cent of men and $29 \%$ of women in this population were obese, while $23 \%$ of the total population had high levels of total cholesterol (TC) and low-density lipoprotein cholesterol (LDL-C). Hypertriglyceridaemia was seen in $4 \%$ of people $^{3}$. Although CVD have heterogeneous aetiologies, environmental factors, including diet, play a major role in their development ${ }^{4}$. The role of nutrients in preventing CVD risk is known ${ }^{5,6}$, but there is little emphasis on overall diet characteristics. Dietary diversity score (DDS), which is an indicator of overall diet, is associated with some nutrient adequacy ratios after adjusting for the effect of energy intake $\mathrm{e}^{7-9}$. Studies suggest that diets with higher variety score are also associated with increased intakes of fibre, vitamin $\mathrm{C}$ and calcium ${ }^{7,8}$, all of which protect against $\mathrm{CVD}^{10-12}$. On the other hand, it is reported that increased variety in the food supply may contribute to the development and maintenance of obesity ${ }^{13-15}$. Therefore evaluating the association between DDS and obesity would be interesting; a relationship may exist between central obesity and DDS. Diverse diets have been shown to protect against chronic diseases such as cancer ${ }^{16}$ while also being associated with prolonged longevity ${ }^{17}$ and improved health status ${ }^{18}$. A significant correlation 
between total food variety and arterial wall index has been shown $^{19}$, as well as a significant association between a poorly diversified diet and hypertension ${ }^{20}$.

Nowadays, nutritional epidemiology has moved away from investigating the effects of a single nutrient to examining the effect of overall diet quality on diet-disease relationships. The Tehran Lipid and Glucose Study (TLGS) ${ }^{21}$ provides the opportunity to assess diet-disease relationships from an epidemiological perspective. Our previous study showed that DDS is a good indicator of nutritional adequacy of the $\operatorname{diet}^{7}$ and so the present study was undertaken to assess the relationship between DDS and CVD risk factors in an urban population of Tehran.

\section{Subjects and methods}

\section{Subjects}

This study was conducted within the framework of the TLGS, a prospective study performed on residents of district 13 of Tehran, with the aims of determining the prevalence of non-communicable disease risk factors and developing a healthy lifestyle to improve these risk factors $^{21}$. A representative sample of 1476 people aged $\geq 3$ years was randomly selected for dietary assessment; among this population, 862 subjects aged $\geq 18$ years were enrolled. Subjects with a prior history of CVD, diabetes and stroke (23 subjects) were excluded because of possible changes in diet. We also excluded subjects whose reported daily energy intake was not between 800 and $4200 \mathrm{kcal}(3347-17537 \mathrm{~kJ})^{22}$ to identify under- and overreporters of food intake (11 subjects). Among the remaining population ( 828 subjects), there were 581 subjects (286 women and 295 men) for whom we had all the relevant data on nutrient adequacy and variety. The proposal of this study was approved by the research council of the Endocrine Research Center of Shaheed Beheshti University of Medical Sciences and informed written consent was obtained from each subject.

\section{Assessment of dietary intake}

Usual dietary intake was assessed using a semi-quantitative food-frequency questionnaire (FFQ). All questionnaires were completed by trained dietitians with at least 5 years of experience in the Nationwide Food Consumption Survey project ${ }^{23,24}$. The FFQ consisted of a list of 168 items and a standard serving size for each (Willett format ${ }^{25}$ ). Participants were asked to report their frequency of consumption of each food item during the previous year on a daily (e.g. bread), weekly (e.g. rice, meat) or monthly (e.g. fish) basis. The reliability of the FFQ in this cohort was evaluated in a randomly chosen subgroup of 132 subjects by comparing the nutrient intakes ascertained from their responses to the FFQ on two occasions (one per year); the FFQ had high reliability ${ }^{26}$. Portion sizes of consumed foods were converted to grams using household measures ${ }^{27}$. Each food and beverage was then coded according to the prescribed protocol and was analysed for content of energy and other nutrients using Nutritionist III software, version 7.0 (N-Squared Computing, Salem, OR, USA), which was designed for evaluation of Iranian foods.

\section{Dietary diversity score}

To score dietary diversity, five main groups - bread/grains, vegetables, fruits, meats and meat substitutes and dairy foods - according to the Food Guide Pyramid were used ${ }^{28}$. These main groups were divided into 23 subgroups according to Haines et $a l^{29}$. The categories show the dietary diversity across the main groups. We expanded the number of bread/grain group categories into seven subgroups (refined bread, biscuits, macaroni, whole bread, cornflakes, rice, refined meal) to reflect the diversity and importance of plant-based foods. Two subgroups of fruits were considered (fruit and fruit juice, berries and citrus) and vegetables were divided into seven subgroups (vegetables, potatoes, tomatoes, starchy vegetables, legumes, yellow vegetables, green vegetables). Four subgroups of meat (red meat, poultry, fish, egg) and three subgroups for dairy (milk, yoghurt, cheese) were considered.

To be counted as a 'consumer' for any of the food group categories, a respondent had to consume at least one-half serving, as defined by the Food Guide Pyramid quantity criteria, during one day. It did not need to be eaten all at once. Each of the five broad food categories received a maximum diversity score of 2 out of the 10 possible score points. For calculation of the score of each group, we divided the number of subgroups consumed by the total number of subgroups in each main group and then we multiplied this by 2 . For example, if a person consumed at least one-half serving from two of seven possible grain categories, he/she would receive a subgroup score of $(2 / 7) \times 2=0.57$ and if a person consumed at least onehalf serving from two of the four possible meat categories, he/she would receive a subgroup score of $(2 / 4) \times 2=1$. Within each of the food groups, the score reflects the percentage of the possible maximum score ${ }^{29}$. Total score was the sum of the scores of the five main groups.

\section{Assessment of other variables}

While the subjects were minimally clothed and without shoes, weight was measured using digital scales and recorded to the nearest $100 \mathrm{~g}$. Height was measured using a measuring tape with the subject in standing position, without shoes, while the shoulders were in a normal state. Body mass index (BMI) was calculated as weight in kilograms divided by the square of height in metres. Waist circumference (WC) was measured at the narrowest level and hip circumference at the maximum level, over light clothing, using an inelastic measuring tape and without any pressure applied to the body surface; measurements were recorded to the nearest $0.1 \mathrm{~cm}$. Waist-to-hip ratio (WHR) was calculated as WC divided by hip 
circumference. To avoid subjective error, all measurements were taken by the same person ${ }^{30}$.

Fasting blood samples for the measurement of glucose and lipid concentrations were drawn after an overnight fast of $12 \mathrm{~h}^{31}$. A 75-g oral glucose tolerance test was administered according to World Health Organization standards ${ }^{32}$ and 2-h post challenge glucose concentration was measured. Blood glucose was measured on the day of blood collection by an enzymatic colorimetric method using glucose oxidase ${ }^{32}$. Serum TC and triglyceride (TG) concentrations were measured using commercially available enzymatic reagents (Pars Azmoon, Iran) adapted to a Selecta autoanalyser ${ }^{31}$. High-density lipoprotein cholesterol (HDL-C) was measured after precipitation of the apolipoprotein B-containing lipoproteins with phosphotungstic acid. LDL-C was calculated according to the Friedewald method ${ }^{33}$. It was not calculated when serum TG concentration was greater than $400 \mathrm{mg} \mathrm{dl}^{-1}$. All samples were analysed when internal quality control checks met acceptable criteria. Inter- and intra-assay coefficients of variation were respectively 2.0 and $0.5 \%$ for TC, and 1.6 and $0.6 \%$ for TG. Blood pressure was measured twice after the participants had been sitting for $15 \mathrm{~min}^{3}$. Additional information on covariates - age, smoking habits ${ }^{34}$, physical activity ${ }^{35}$, medical history and current use of medications ${ }^{34}$ - was obtained using validated questionnaires, as reported earlier.

\section{Definition of terms}

Obesity was defined ${ }^{36}$ as BMI $\geq 30 \mathrm{~kg} \mathrm{~m}^{-2}$. According to the Adult Treatment Panel III guidelines of the National Cholesterol Education Program ${ }^{37}$, hypercholesterolaemia was considered as TC $\geq 240 \mathrm{mg} \mathrm{dl}^{-1}$, hypertriglyceridaemia as TG $\geq 200 \mathrm{mg} \mathrm{dl}^{-1}$, low HDL-C as $<40 \mathrm{mg} \mathrm{dl}^{-1}$ and high LDL-C as $\geq 160 \mathrm{mg} \mathrm{dl}^{-1}$. Previously undiagnosed diabetes was defined ${ }^{38}$ as fasting plasma glucose concentration $\geq 126 \mathrm{mg} \mathrm{dl}^{-1}$ or 2 -h post challenge glucose concentration $\geq 200 \mathrm{mg} \mathrm{dl}^{-1}$. Hypertension was defined as systolic blood pressure $\geq 140 \mathrm{mmHg}$ or diastolic blood pressure $\geq 90 \mathrm{mmHg}$ or current use of antihypertensive medication on the basis of the sixth report of the Joint National Committee on Prevention, Detection, Evaluation and Treatment of High Blood Pressure ${ }^{39}$.

\section{Statistical methods}

The Statistical Package for the Social Sciences, version 9.05 (SPSS Inc., Chicago, IL, USA) was used for all statistical analyses. In separate models, there were no significant interactions by sex on the association of DDS and CVD risk factors. Subjects were categorised based on quartile cut points of the DDS: Q1, $<3.5$; Q2, 3.5 to $<6$; Q3, 6 to $<8$; $\mathrm{Q} 4, \geq 8$. The numbers of subjects in the quartiles are different because we used quartile cut points for categorising subjects, not the distribution of subjects based on quartiles. Cut points for quartiles of the diversity score for whole grains were as follows: Q1, <0.6; Q2, 0.6 to $<1.0 ;$ Q3, 1.0 to $<1.4 ;$ Q4, $\geq 1$.4. Cut points for quartiles of the diversity score for vegetables also were calculated:

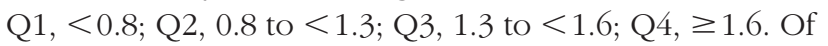
course, we calculated all cut points for quartiles of the diversity score for each food group. Significant differences in general characteristics across quartile categories of DDS were searched using one-way analysis of variance and Tukey's test. We determined multivariate-adjusted means (age, sex, physical activity, smoking, BMI, WHR, total energy intake, percentage of energy from fat, current use of antihypertensive medication and oestrogen replacement therapy) for CVD risk factors and age-, sex- and energy-adjusted means for dietary variables across quartiles of DDS using the GLM procedure. Analysis of covariance with the correction of Tukey's test was used to compare these means. Logistic regression models controlled for age (years), energy intake $\left(\mathrm{kcalday}^{-1}\right)$, percentage of energy from fat, carbohydrate and other food group intake, use of blood pressure medication (yes or no), cigarette smoking (categorical: daily smoker, current smoker, ex-smoker, non-smoker), physical activity level (light, moderate, heavy) and current oestrogen replacement therapy among women (yes or no) were used. In all multivariate models, Q4 of the DDS was considered as reference. The Mantel-Haenszel extension test was performed to assess the overall trend of increasing quartile categories of DDS associated with an increasing prevalence of risk factors.

\section{Results}

Mean ( \pm standard deviation (SD)) DDS was $6.15 \pm 1.02$. The maximum and minimum scores for diversity respectively were related to fruit $(1.48 \pm 0.60)$ and grain $(0.85 \pm 0.24)$ groups. Mean $( \pm S D)$ age, anthropometric measures and cardiovascular risks, as well as the distribution of subjects with regard to obesity, smoking, physical activity status and current oestrogen use, are shown in Table 1 across quartile categories of DDS. Those in the lower category of DDS were younger and had lower BMI. There was no significant difference regarding WC and WHR across DDS quartiles. Most subjects had light physical activity in all quartile groups of DDS. There was no regular trend across the quartiles of DDS to be a daily smoker. The prevalence of obesity was higher among those in the upper category of DDS, compared with the lower one. Multivariate-adjusted means for metabolic risk factors showed that higher DDS was associated with lower levels of LDL-C, systolic and diastolic blood pressure.

Age-, sex- and energy-adjusted means for dietary variables across DDS quartile categories are presented in Table 2. A higher DDS was associated with a healthier diet. Those in the upper category also consumed less cholesterol and meat, and more dietary fibre, fruit, vegetables and vegetable oil. The higher DDS was 
Table 1 Characteristics* of Tehran Lipid and Glucose Study participants by quartile of dietary diversity score (DDS)

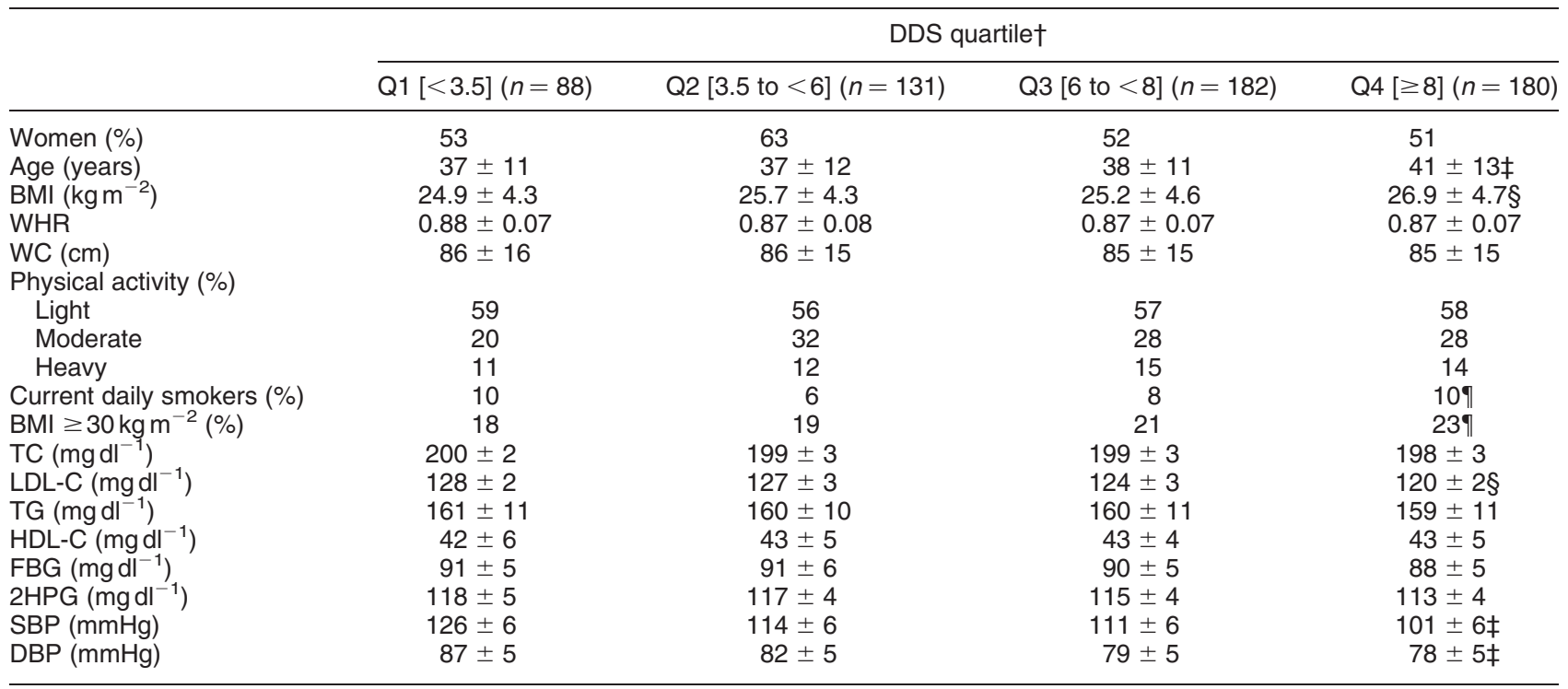

BMI - body mass index; WHR - waist-to-hip ratio; WC - waist circumference; TC - total cholesterol; LDL-C - low-density lipoprotein cholesterol; TG - triglycerides; HDL-C - high-density lipoprotein cholesterol; FBG - fasting blood glucose; 2HPG - 2-h postprandial glucose; SBP - systolic blood pressure; DBP - diastolic blood pressure.

${ }^{*}$ Data are expressed as mean \pm standard deviation unless indicated otherwise.

† Quartile cut points in square brackets.

$\ddagger P<0.01$ (analysis of variance (ANOVA) with Tukey's test).

$\S P<0.05$ (ANOVA with Tukey's test).

I $P<0.05$ (chi-square test).

Table 2 Dietary intakes* of Tehran Lipid and Glucose Study participants by quartile of dietary diversity score (DDS)

\begin{tabular}{|c|c|c|c|c|}
\hline \multirow[b]{2}{*}{ Dietary intake } & \multicolumn{4}{|c|}{ DDS quartile† } \\
\hline & Q1 $[<3.5](n=88)$ & Q2 [3.5 to $<6](n=131)$ & Q3 [6 to $<8$ ] $(n=182)$ & Q4 $[\geq 8](n=180)$ \\
\hline \multicolumn{5}{|l|}{ Nutrients } \\
\hline Total energy (kcal day ${ }^{-1}$ ) & 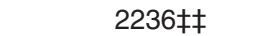 & 2318 & 2456 & 2523 \\
\hline Carbohydrate ( $\%$ of total energy) & 60 & 58 & 58 & 58 \\
\hline Protein (\% of total energy) & 12 & 11 & 12 & 11 \\
\hline Fat ( $\%$ of total energy) & 28 & 31 & 30 & 31 \\
\hline Cholesterol (mg day ${ }^{-1}$ ) & 183 & 177 & $169 \S \S$ & $162 \S \S$ \\
\hline Dietary fibre $\left(\mathrm{g} \mathrm{day}^{-1}\right)^{\prime}$ & 10 & 14 & 17 & $21 \S \S$ \\
\hline Vitamin C (mg day $\left.{ }^{-1}\right)^{\prime}$ & 112 & 156 & 189 & $210 \S \S$ \\
\hline Calcium (mg day $\left.{ }^{-1}\right)$ & 817 & 850 & 910 & $960 \S \S$ \\
\hline \multicolumn{5}{|l|}{ Foods $\left(\mathrm{g} \mathrm{day}^{-1}\right)$} \\
\hline Fruitł & 171 & 189 & 196 & $220 \S \S$ \\
\hline Vegetables§ & 230†‡ & 291 & 310 & 319 \\
\hline Meatף & 111 & 109 & 108 & 107 \\
\hline Whole grains\| & 19ł‡ & 38㧊 & 49ł‡ & 61㧊 \\
\hline Refined grains ${ }^{\star *}$ & 81㧊 & $61 \neq \ddagger$ & 50 & 45 \\
\hline Dairyt† & 201 & 212 & 218 & $230 \S \S$ \\
\hline Vegetable oils & 91 & 117 & 126 & $131 \S \S$ \\
\hline Animal oils & 110 & 88 & 80 & $76 \S \S$ \\
\hline
\end{tabular}

${ }^{*}$ Reported nutrient and food intakes were adjusted for age, sex and total energy intake.

† Quartile cut points in square brackets.

$\ddagger$ Includes apples, oranges, bananas, peaches, grapes, strawberries, pears, watermelon, grapefruit, prunes, pomegranates, kiwi, persimmons, raisins, figs, coconuts, apricots and sweet lemons.

$\S$ Includes onions, cucumbers, lettuces, carrots, cauliflower, Brussels sprouts, kale, cabbage, spinach, mixed vegetables, corn, green beans, green peas, peppers, beets, potatoes, tomatoes, broccoli and celery.

I Includes beef, liver, chicken hearts and kidneys, hamburger, sausages, processed meats, meat in a sandwich, tuna and other fish.

|| Includes dark breads (sangak, barbari, taftoon), barley bread, cornflakes, bulgur and germs.

${ }_{* \star}$ Includes white breads (lavash, baguette), noodles, pasta, rice, toasted bread, milled barley, sweet bread, white flour, starch and biscuits. $\dagger \dagger$ Includes milk, yoghurt and cheeses.

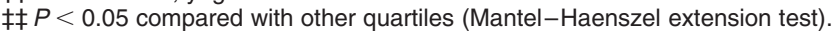

$\S \S P<0.05$ compared with first quartile (Mantel-Haenszel extension test). 
Table 3 Odds ratio (95\% confidence interval)* of having cardiovascular risk factors by quartile of the diversity score for whole grains

\begin{tabular}{|c|c|c|c|c|c|}
\hline \multirow[b]{2}{*}{ Risk factor } & \multicolumn{4}{|c|}{ Quartile of diversity score for whole grainst } & \multirow[b]{2}{*}{$P$ for trend } \\
\hline & $\begin{array}{l}\text { Q1 }[<0.6] \\
(n=88)\end{array}$ & $\begin{array}{c}\text { Q2 }[0.6 \text { to }<1.0] \\
(n=131)\end{array}$ & $\begin{array}{c}\text { Q3 }[1.0 \text { to }<1.4] \\
(n=182)\end{array}$ & $\begin{array}{l}\text { Q4 }[\geq 1.4] \\
(n=180)\end{array}$ & \\
\hline Hypercholesterolaemia (TC $\geq 240 \mathrm{mg} \mathrm{dl}^{-1}$ ) & $1.36(0.96-1.61)$ & $1.26(0.63-1.41)$ & $1.21(0.78-1.61)$ & 1.00 & NS \\
\hline Low HDL-C (<40 $\left.\mathrm{mg} \mathrm{dl}^{-1}\right)$ & $1.13(0.81-1.61)$ & $1.08(0.80-1.56)$ & $1.06(0.88-1.31)$ & 1.00 & NS \\
\hline Hypertriglyceridaemia $\left(\mathrm{TG} \geq 200 \mathrm{mg} \mathrm{dl}^{-1}\right)$ & $1.41(1.09-1.78) \ddagger$ & $1.23(1.01-1.56) \ddagger$ & $1.05(0.87-1.23)$ & 1.00 & $<0.04$ \\
\hline Diabetes (FBG $\geq 126 \mathrm{mg} \mathrm{dl}^{-1}$ or $2 \mathrm{HPG} \geq 200 \mathrm{mg} \mathrm{dl}^{-1}$ ) & $1.45(1.09-1.88) \ddagger$ & $1.26(1.05-1.55) \ddagger$ & $1.11(0.89-1.44)$ & 1.00 & $<0.04$ \\
\hline Hypertension (SBP $\geq 140 \mathrm{mmHg}$ or DBP $\geq 90 \mathrm{mmHg}$ ) & $1.22(0.88-1.51)$ & $1.18(0.84-1.36)$ & $1.15(0.55-1.43)$ & 1.00 & NS \\
\hline
\end{tabular}

TC - total cholesterol; HDL-C - high-density lipoprotein cholesterol; TG - triglycerides; FBG - fasting blood glucose; 2HPG - 2-h postprandial glucose; SBP - systolic blood pressure; DBP - diastolic blood pressure; NS - not significant.

*Odds ratios are adjusted for age, sex, smoking, physical activity, body mass index (BMI), waist-to-hip ratio (WHR), total energy intake, percentage energy from fat, carbohydrate and other food group intake, use of blood pressure medication and use of oestrogen. BMI and WHR were not adjusted when testing the association between obesity and dietary diversity score.

†Quartile cut points in square brackets.

$\ddagger P<0.05$ compared with the fourth quartile.

positively associated with total intakes of dietary fibre $(r=0.43)$, calcium $(r=0.51)$ and vitamin C $(r=0.48)$.

Table 3 shows the odds ratio (OR) and 95\% confidence interval (CI) for the incidence of CVD risk factors across quartile categories of the diversity score for whole grains. As can be seen, the probability of having diabetes (OR among quartiles, Q1-Q4: 1.45, 1.26, 1.11 and 1.00, respectively; $P$ for trend $=0.04$ ) and hypertriglyceridaemia (OR, Q1-Q4: 1.41, 1.23, 1.05 and 1.00, respectively; $P$ for trend $=0.04$ ) decreased with increasing quartile of the diversity score for whole grains.

The OR and 95\% CI for CVD risk factors across quartile categories of the diversity score for vegetables are shown in Table 4 . The probability of having obesity (OR, Q1-Q4: $1.39,1.06,1.03$ and 1.00, respectively; $P$ for trend $=0.03$ ), hypercholesterolaemia (OR, Q1-Q4: 1.46, 1.28, 1.11 and 1.00 , respectively; $P$ for trend $=0.03$ ), hypertension (OR, Q1-Q4: 1.32, 1.17, 1.13 and 1.00, respectively; $P$ for trend $=0.03)$ and high LDL-C (OR, Q1-Q4: 1.25, 1.12, 1.07 and 1.00 , respectively; $P$ for trend $=0.04$ ) decreased with increasing quartile of the diversity score for vegetables.

Analysis of data according to diversity score for dairy also showed that the odds of having hypertension decreased with increasing quartile of the dairy diversity score (OR, Q1-Q4: 1.42, 1.19, 1.13 and 1.00, respectively; $P$ for trend $=0.03$ ).

Figure 1 shows the OR and 95\% CI of having hypercholesterolaemia, high LDL-C and hypertriglyceridaemia across quartiles of the DDS. OR are adjusted for age, sex, smoking, physical activity, BMI, WHR, total energy intake, percentage energy from fat, carbohydrate and other food group intake, use of blood pressure medication and use of oestrogen. The probability of having hypercholesterolaemia and high LDL-C decreased with increasing quartile of DDS ( $P$ for trend $=0.02$ and 0.04 , respectively).

Figure 2 shows the OR and 95\% CI for having hypertension, diabetes and obesity across the quartiles of DDS. OR are adjusted for age, sex, smoking, physical activity, BMI, WHR, total energy intake, percentage energy from fat, carbohydrate and other food group intake, use of blood pressure medication and use of oestrogen. The probability of having hypertension and diabetes decreased with increasing quartile of DDS ( $P$ for trend $=0.03$ for both), but the probability of being obese increased across DDS quartiles ( $P$ for trend $=0.03$ ).

Table 4 Odds ratio (95\% confidence interval)* of having cardiovascular risk factors by quartile of the diversity score for vegetables

\begin{tabular}{|c|c|c|c|c|c|}
\hline \multirow[b]{2}{*}{ Risk factor } & \multicolumn{4}{|c|}{ Quartile of diversity score for vegetables† } & \multirow[b]{2}{*}{$P$ for trend } \\
\hline & $\begin{array}{c}\text { Q1 }[<0.8] \\
(n=88)\end{array}$ & $\begin{array}{c}\text { Q2 }[0.8 \text { to }<1.3] \\
(n=131)\end{array}$ & $\begin{array}{c}\text { Q3 }[1.3 \text { to }<1.6] \\
(n=182)\end{array}$ & $\begin{array}{l}\text { Q4 }[\geq 1.6] \\
(n=180)\end{array}$ & \\
\hline Obesity (BMI $\left.\geq 30 \mathrm{~kg} \mathrm{~m}^{-2}\right)$ & $1.39(1.01-1.51) \ddagger$ & $1.06(0.91-1.28)$ & $1.03(0.71-1.36)$ & 1.00 & $<0.03$ \\
\hline Hypercholesterolaemia (TC $\geq 240 \mathrm{mg} \mathrm{dl}^{-1}$ ) & $1.46(1.20-1.69) \ddagger$ & $1.28(1.08-1.73) \ddagger$ & $1.11(1.01-1.49) \ddagger$ & 1.00 & $<0.03$ \\
\hline Low HDL-C $\left(<40 \mathrm{mg} \mathrm{dl}^{-1}\right)$ & $1.06(0.83-1.51)$ & $1.03(0.60-1.56)$ & $1.02(0.81-1.41)$ & 1.00 & NS \\
\hline Hypertriglyceridaemia $\left(T G \geq 200 \mathrm{mg} \mathrm{dl}^{-1}\right)$ & $1.21(0.91-1.78)$ & $1.17(0.89-1.46)$ & $1.15(0.77-1.25)$ & 1.00 & NS \\
\hline Diabetes (FBG $\geq 126 \mathrm{mg} \mathrm{dl}^{-1}$ or $2 \mathrm{HPG} \geq 200 \mathrm{mg} \mathrm{dl}^{-1}$ ) & $1.12(0.54-1.88)$ & $1.06(0.51-1.55)$ & $1.05(0.89-1.34)$ & 1.00 & NS \\
\hline Hypertension (SBP $\geq 140 \mathrm{mmHg}$ or DBP $\geq 90 \mathrm{mmHg}$ ) & $1.32(0.86-1.61)$ & $1.17(0.85-1.36)$ & $1.13(0.55-1.43)$ & 1.00 & $<0.03$ \\
\hline High LDL- $\mathrm{C}\left(\geq 160 \mathrm{mg} \mathrm{dl}^{-1}\right)$ & $1.25(0.76-1.51)$ & $1.12(0.86-1.50)$ & $1.07(0.61-1.31)$ & 1.00 & $<0.04$ \\
\hline
\end{tabular}

BMI, body mass index; TC - total cholesterol; HDL-C - high-density lipoprotein cholesterol; TG - triglycerides; FBG - fasting blood glucose; $2 \mathrm{HPG} \mathrm{-} \mathrm{2-h}$ postprandial glucose; SBP - systolic blood pressure; DBP - diastolic blood pressure; LDL-C low-density lipoprotein cholosterol; NS - not significant.

* Odds ratios are adjusted for age, sex, smoking, physical activity, body mass index, waist-to-hip ratio, total energy intake, percentage energy from fat, carbohydrate and other food group intake, use of blood pressure medication and use of oestrogen.

†Quartile cut points in square brackets.

$\ddagger P<0.05$ compared with the fourth quartile. 

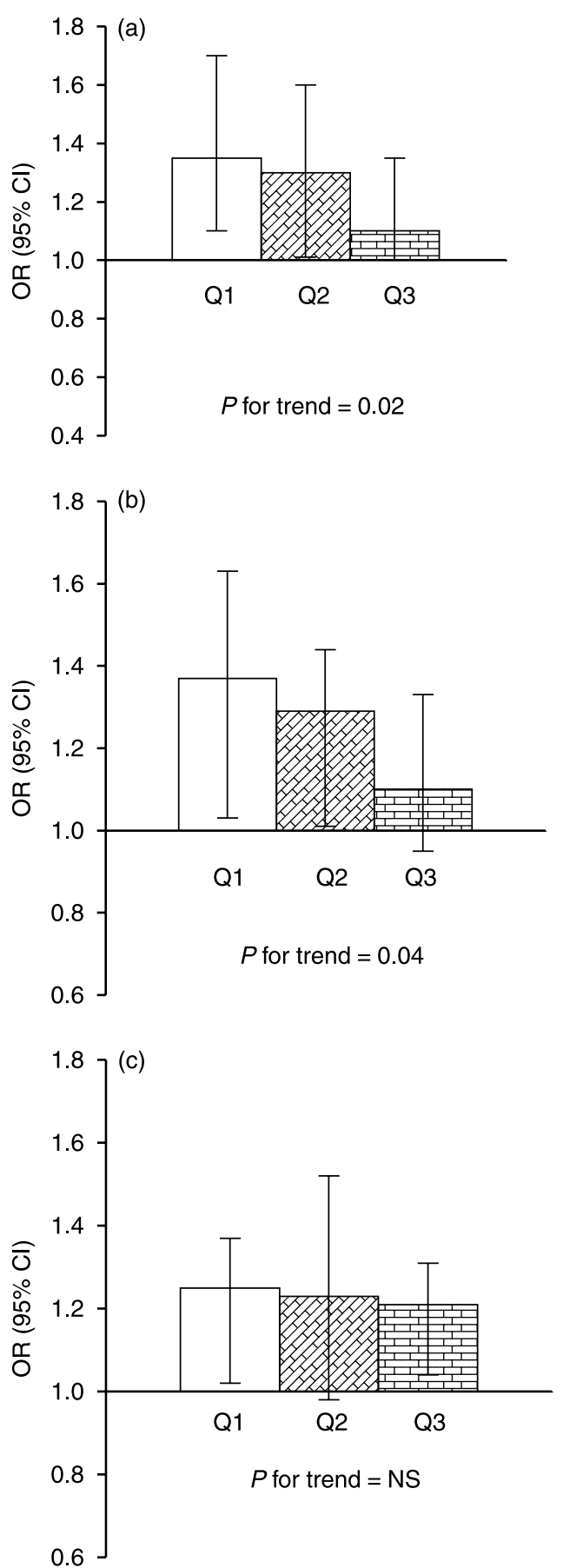

Fig. 1 Multivariate-adjusted odds ratio (OR) and 95\% confidence interval ( $\mathrm{Cl}$; shown by vertical bars) of having hypercholesterolaemia (a), high low-density lipoprotein cholesterol (LDL-C) (b) and hypertriglyceridaemia (c) across quartiles of dietary diversity score (DDS). The probability of having hypercholesterolaemia and high LDL-C decreased with increasing quartile of DDS. OR are adjusted for age, sex, smoking, physical activity, body mass index, waist-to-hip ratio, total energy intake, percentage energy from fat, carbohydrate and other food group intake, use of blood pressure medication and use of oestrogen. Q1-Q3 - quartiles 1 to 3 of DDS, quartile $4(\mathrm{Q} 4)$ was the reference $(\mathrm{OR}=1.00)$; NS not significant. Quartile cut points of DDS are as follows: Q1, $<3.5$; Q2, 3.5 to $<6$, Q3; 6 to $<8$; Q4, $\geq 8$. Hypercholesterolaemia is defined as total cholesterol $\geq 240 \mathrm{mg} \mathrm{dl}^{-1}$, high LDL-C as $\geq 160 \mathrm{mg} \mathrm{dl}^{-1}$ and hypertriglyceridaemia as triglycerides $\geq 200 \mathrm{mg} \mathrm{dl}^{-1}$

\section{Discussion}

The present study, conducted among a representative sample of Tehranian adults, showed an inverse association between DDS and some CVD risk factors like hypertension, hypercholesterolaemia, high LDL-C and diabetes. To the best of our knowledge, this is one of the first studies reporting the association of overall diversity score and the diversity score of different food groups with CVD risk factors. Bernstein et al. ${ }^{40}$ mentioned the association between DDS and serum lipid level, but there are no data specific to the diversity score for individual food groups. As previous research in the field of DDS-chronic disease relationships has focused mostly on cancer ${ }^{41,42}$, the present study offers the opportunity of studying other chronic diseases.

The favourable association between DDS and metabolic risks may be attributed to the healthier lifestyle (higher consumption of fibre, fruit, vegetables and vegetable oil, lower consumption of meat and cholesterol) associated with higher DDS. Of course, changing the dietary pattern among patients with diabetes and hypercholesterolaemia may confound the association between DDS and metabolic risks. Although people in the higher categories of DDS had higher energy intake and were more obese, this higher amount of energy could be attributed to the increased consumption of vegetables, fruit, vegetable oil and dairy, i.e. healthy nutrition patterns. Therefore, it seems that it is better to suggest increasing the diversity scores for vegetables and fruit and not to increase the diversity scores for fat and sugar, which are related to being more obese.

A previous study in this area of Tehran showed DDS to be correlated with nutrient adequacy ratio of vitamin $\mathrm{C}$ and calcium $^{11}$. As mentioned in previous studies ${ }^{11,12,43}$, these two nutrients have a negative association with CVD such as hypertension. Osborne et $a l .{ }^{44}$ found that calcium had an important role in blood pressure regulation and that adequate intake of calcium might reduce the risk of hypertension. Some mechanisms responsible for this effect of calcium may be the natriuretic effect, regulation of the sympathetic nervous system, and prevention of vessel constriction. In Azizi et al.'s study ${ }^{11}$ an inverse correlation between blood pressure and calcium intake was seen. On the other hand, calcium could bind to fatty acids and inhibit the absorption of fats ${ }^{12}$. Recently, it has been demonstrated that dairy consumption is inversely associated with BMI and that calcium plays an essential role in this issue ${ }^{43}$. On the whole, higher DDS is associated with higher intake of calcium and perhaps better cardiovascular status. In the present study, a higher diversity score for dairy products was associated with lower odds of having hypertension. Therefore, consumption of various low-fat dairy products might be a good way for preventing hypertension. Of course, consideration of the fat content of dairy products is an important issue, and if it is not paid sufficient attention, may result in an inverse outcome. Regarding vitamin 
C, Azizi et al. ${ }^{11}$ showed that high vitamin $\mathrm{C}$ intake is a predictor of high HDL-C in the TLGS population and also found an inverse relationship between vitamin $\mathrm{C}$ intake and hypertension.

Previous studies showed that DDS is a good indicator of diet quality and our study has shown that it may be
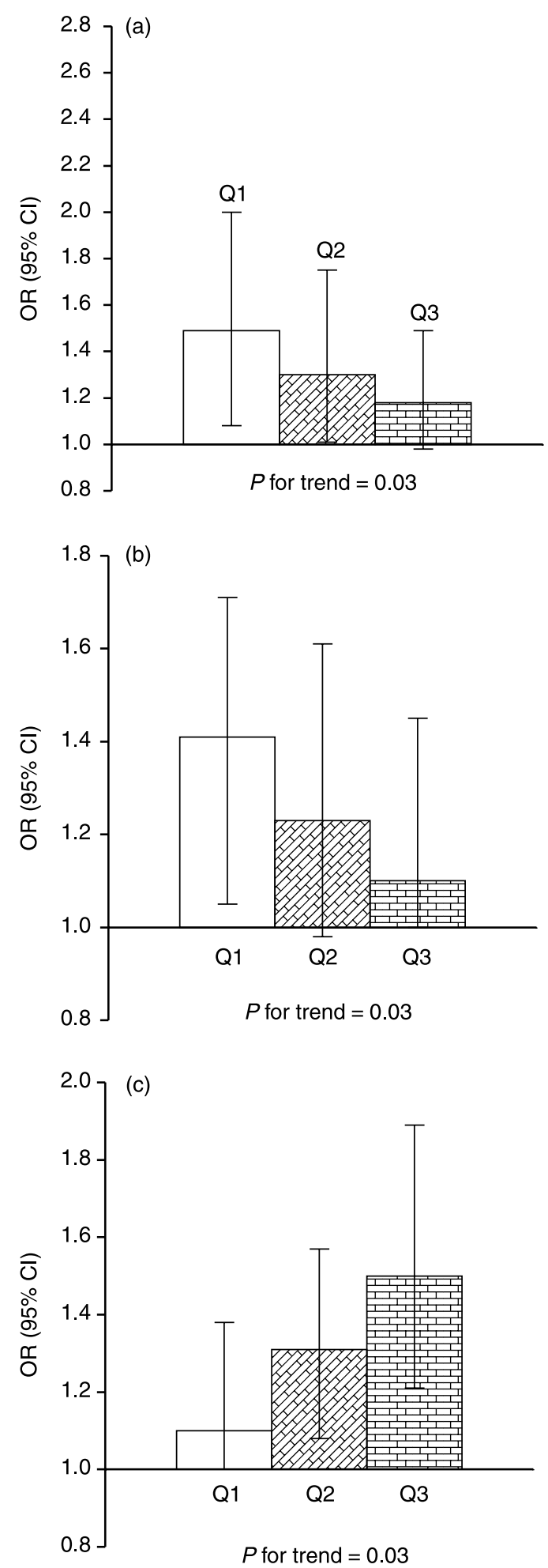

correlated with some CVD risks - higher DDS was associated with lower odds of having hypercholesterolaemia, hypertension and diabetes. Therefore, public education to improve within- and between-group dietary variety as well as to control energy intake may be beneficial. The results of the present study also show that the variety score of individual food groups might be related to particular metabolic risk factors. Our study demonstrates that not only the amount of food group intake but also the variety contributes to health and disease, e.g. the odds of having diabetes and hypertriglyceridaemia decreased with increasing quartile of the diversity score for whole grains. Fung et al. ${ }^{22}$ showed that higher consumption of whole grains is associated with better glycaemic control. A crossover intervention study also supports the hypothesis that diets rich in whole-grain foods are associated with lower insulin concentrations ${ }^{45}$. In the Framingham offspring cohort, intake of whole grains was favourably associated with several metabolic risk factors of this syndrome, including central obesity, insulin sensitivity and dyslipidaemia ${ }^{46}$. The variety score for vegetables in the present study was related to the most cardiovascular risks. It seems that emphasis on the variety score for the vegetables group might be related to a lower chance of having metabolic risks. Moreover, increasing the variety of vegetables might not be associated with high energy intake and increasing chance of obesity.

The favourable association between higher DDS and variety scores for food groups and CVD risks may be attributed to the healthier lifestyle associated with greater variety in food intakes. However, the higher odds of having cardiovascular risks persisted in multivariate models accounting for known coronary risk factors.

As higher DDS is associated with higher energy intake $^{47}$ and therefore may be associated with obesity ${ }^{13}$, it is obviously important to emphasise that the recommendation to increase dietary diversity be associated with the consideration of energy intake. It is better to increase the diversity score for healthy food

Fig. 2 Multivariate-adjusted odds ratio (OR) and 95\% confidence interval ( $\mathrm{Cl}$; shown by vertical bars) of having hypertension (a), diabetes (b) and obesity (c) across quartiles of dietary diversity score (DDS). The probability of having hypertension and diabetes decreased with increasing quartile of DDS, but the probability of having obesity increased with increasing DDS quartile. OR are adjusted for age, sex, smoking, physical activity, body mass index (BMI), waist-to-hip ratio, total energy intake, percentage energy from fat, carbohydrate and other food group intake, use of blood pressure medication and use of oestrogen. Q1-Q3 - quartiles 1 to 3 of DDS, quartile 4 (Q4) was the reference $(\mathrm{OR}=1.00)$. Quartile cut points of DDS are as follows: $Q 1,<3.5$; Q2, 3.5 to $<6$; Q3, 6 to $<8 ; \mathrm{Q} 4, \geq 8$. Hypertension is defined as systolic blood pressure $\geq 140 \mathrm{mmHg}$ or diastolic blood pressure $\geq 90 \mathrm{mmHg}$ or current use of antihypertensive medication; diabetes as fasting plasma glucose concentration $\geq 126 \mathrm{mg} \mathrm{dl}^{-1}$ or 2-h post challenge glucose concentration $\geq 200 \mathrm{mg} \mathrm{dl}^{-1}$; and obesity as $\mathrm{BMI} \geq 30 \mathrm{~kg} \mathrm{~m}^{-2}$ 
groups such as vegetables and whole grains. Unfortunately, there is no study explaining the association of CVD risks with DDS and variety scores for various food groups with which we can compare our results.

We used categorical variables in this study, which has several advantages. First, the investigator can visualise directly how the actual numbers of cases and non-cases vary by level of intake. Second, the use of multiple categories makes no assumptions about the doseresponse relationship, and it is therefore possible to visualise whether this is most compatible with a linear trend or some non-linear alternative. Third, the use of categories constrains any undue influence of outlying data points, which are the observations most likely to be affected by errors in data collection or processing. However, this categorisation of the variables may cause data $\operatorname{loss}^{48}$.

There are several limitations that should be considered when examining the results of this study. First, we used cross-sectional data to identify the association of DDS with CVD risks, which does not allow us to make causal inferences. However, it must be kept in mind that appropriate analysis of cross-sectional data represents a valuable initial step in identifying diet-disease relationships. Moreover, prospective cohort studies and clinical trials have their own weaknesses. Future studies using longitudinal data will provide stronger evidence on this association. Second, high scores on dietary diversity appear to reflect an overall healthier lifestyle that may not have been accurately captured and controlled in our analysis, resulting in residual confounding. Third, subjects with known coronary artery disease, diabetes and stroke were excluded from the study. These exclusions may have reduced the likelihood of finding significant trends in odds of having metabolic risks across quartile categories of DDS. Chronic diseases are heterogeneous and besides dietary pattern, other factors such as hereditary factors may need to be considered. Additionally, most of the risk factors are interrelated and this could confound the relationship between DDS and CVD risk factors. However, our study has several strengths. Use of a population-representative sample of Tehran, logistic regression models and simultaneous adjustment of confounding variables in the association of DDS with the metabolic syndrome allowed us to find a cross-sectional relationship between DDS and CVD risks and some of its features such as hypertension, hypercholesterolaemia, high LDL-C, obesity and diabetes.

In conclusion, DDS is inversely associated with CVD risks. Therefore, efforts to increase the diversity score of diets by emphasising the diversity scores for vegetable and fruit groups and controlling total energy intake may be beneficial. Besides following the recommendations of dietary guidelines, this procedure might be associated with reductions in the incidence of metabolic risks.

\section{Acknowledgements}

This work was supported by a grant from the Endocrine Research Center (ERC) of Shaheed Beheshti University of Medical Sciences. The research project was supported by NRCI Research Projects grant no. 121 from the National Research Council of the Islamic Republic of Iran. We express appreciation to the participants for their enthusiastic cooperation and also to the staff of ERC for their valuable support. We would like to acknowledge the help given to us by Dr LE Torheim of Akershus University College, Lillestrom, Norway, for providing her PhD thesis and articles on dietary scores and related issues.

\section{References}

1 Kromhout D. Epidemiology of cardiovascular diseases in Europe. Public Health Nutrition 2001; 4: 441-57.

2 Azizi F. Tehran Lipid and Glucose Study. The Final Report of First Phase, 1st ed. Tehran: Endocrine Research Center, Shaheed Beheshti University of Medical Sciences, 2001; 49, 63, 91, 96, 98.

3 Azizi F, Ghanbarian A, Madjid M, Rahmani M. Distribution of blood pressure and prevalence of hypertension in Tehran adult population: Tehran Lipid and Glucose Study (TLGS), 1999-2000. Journal of Human Hypertension 2002; 16: 305-12.

4 Hollenberg NK. Genetic versus environmental etiology of the metabolic syndrome among male and female twins. Current Hypertension Reports 2002; 4: 178.

5 Rimm EB, Willett WC, Hu FB, Sampson L, Colditz GA, Manson JE, et al. Folate and vitamin $\mathrm{B}_{6}$ from diet and supplements in relation to risk of coronary heart disease among women. Journal of the American Medical Association 1998; 279: 359-64.

6 Wolk A, Manson JE, Stampfer MJ, Colditz GA, Hu FB, Speizer $\mathrm{FE}$, et al. Long-term intake of dietary fiber and decreased risk of coronary heart disease among women. Journal of the American Medical Association 1999; 281: 1998-2004.

7 Mirmiran P, Azadbakht L, Esmaillzadeh A, Azizi F. Dietary diversity score in adolescents - a good indicator of the nutritional adequacy of diets: Tehran Lipid and Glucose Study. Asia Pacific Journal of Clinical Nutrition 2004; 13: 56-60.

8 Hatloy A, Torheim LE, Oshaug A. Food variety - a good indicator of nutritional adequacy of the diet? A case study from an urban area in Mali, West Africa. European Journal of Clinical Nutrition 1998; 52: 891-8.

9 Drewnowski A, Ahlstrom Henderson S, Driscoll A, Rolls BJ. The dietary variety score: assessing diet quality in healthy young and older adults. Journal of the American Dietetic Association 1997; 97: 266-71.

10 Jorde R, Bonaa KH. Calcium from dairy products, vitamin D intake, and blood pressure: the Tromso Study. American Journal of Clinical Nutrition 2000; 71: 1530-5.

11 Azizi F, Mirmiran P, Azadbakht L. Predictors of cardiovascular risk factors in Tehranian adolescents: Tehran Lipid and Glucose Study. International Journal for Vitamin and Nutrition Research 2004; 74: 307-12.

12 Weaver CM, Heaney RP. Calcium. In: Shils ME, Olson JA, Shike M, Ross AC, eds. Modern Nutrition in Health and Disease, 9th ed. Philadelphia, PA: Lippincott, Williams and Wilkins, 1998; 148.

13 Raynor HA, Epstein LH. Dietary variety, energy regulation, and obesity. Psychological Bulletin 2001; 127: 325-41. 
14 Kennedy E. Dietary diversity, diet quality, and body weight regulation. Nutrition Reviews 2004; 62: S78-81.

15 Raynor HA, Jeffery RW, Tate DF, Wing RR. Relationship between changes in food group variety, dietary intake, and weight during obesity treatment. International Journal of Obesity and Related Metabolic Disorders 2004; 28: 813-20.

16 McCullough ML, Feskanich D, Stampfer MJ, Giovannucci EL, Rimm EB, Hu FB, et al. Diet quality and major chronic disease risk in men and women: moving toward improved dietary guidance. American Journal of Clinical Nutrition 2002; 76: 1261-71.

17 Kant AK, Schatzkin A, Ziegler RG. Dietary diversity and subsequent cause of specific mortality in the NHANES I epidemiologic follow up study. Journal of the American College of Nutrition 1995; 14: 233-8.

18 Hodgson JM, Hsu-Hage BH, Wahlqvist ML. Food variety as a quantitative descriptor of food intake. Ecology of Food and Nutrition 1994; 32: 137-48.

19 Wahlqvist ML, Lo CS, Myers KA. Food variety is associated with less macrovascular disease in those with type II diabetes and their healthy controls. Journal of the American College of Nutrition 1989; 8: 515-23.

20 Miller WL, Crabtree BF, Evans DK. Exploratory study of the relationship between hypertension and diet diversity among Saba Islanders. Public Health Reports 1992; 107: 426-32.

21 Azizi F, Rahmani M, Emami H, Madjid M. Tehran Lipid and Glucose Study: rationale and design. CVD Prevention 2000; 3: $242-7$.

22 Fung TT, Rimm EB, Spiegelman D, Rifai N, Tofler GH, Willett $\mathrm{WC}$, et al. Association between dietary patterns and plasma biomarkers of obesity and cardiovascular diseases risk. American Journal of Clinical Nutrition 2001; 73: 61-7.

23 Kimiagar SM, Ghaffarpour M, Houshiar-Red A, Hormozdyari $\mathrm{H}$, Zellipour L. Food consumption pattern in the Islamic Republic of Iran and its relation to coronary heart disease. East Mediterranean Health Journal 1998; 4: 539-47.

24 Kimiagar M. National Food Consumption Survey. Tehran: National Nutrition and Food Technology Research Institute, 1995.

25 Rimm EB, Giovannucci EL, Stampfer MJ, Colditz GA, Litin LB, Willett WC. Reproducibility and validity of an expanded selfadministered semiquantitative food frequency questionnaire among male health professionals. American Journal of Epidemiology 1992; 135: 1114-26.

26 Esmaillzadeh A, Mirmiran P, Azizi F. Whole-grain intake and the prevalence of hypertriglyceridemic waist phenotype in Tehranian adults. American Journal of Clinical Nutrition 2005; 81: 55-63.

27 Ghafarpour M, Houshiar-Rad A, Kianfar H. The Manual for Housebold Measures, Cooking Fields Factors and Edible Portion of Food. Tehran: Keshavarzi Press, 1999.

28 US Department of Agriculture (USDA). Food Guide Pyramid. Washington, DC: USDA, 1996.

29 Haines PS, Siega-Riz AM, Popkin BM. The Diet Quality Index revised: a measurement instrument for populations. Journal of the American Dietetic Association 1999; 99: 697-704.

30 Mirmiran P, Esmaillzadeh A, Azizi F. Detection of cardiovascular risk factors by anthropometric measures in Tehran adults: receiver operating characteristic (ROC) curve analysis. European Journal of Clinical Nutrition 2004; 58: 1110-8.

31 Azizi F, Rahmani M, Ghanbarian A, Emami H, Salehi P, Mirmiran $\mathrm{P}$, et al. Serum lipid levels in an Iranian adult population: Tehran Lipid and Glucose Study. European Journal of Epidemiology 2003; 18: 311-9.

32 World Health Organization (WHO) Expert Committee on Diabetes Mellitus. Second Report on Diabetes Mellitus. WHO Technical Report Series No. 646. Geneva: WHO, 1980.

33 Friedewald WT, Levy RI, Fredrickson DS. Estimation of the concentration of low-density lipoprotein cholesterol in plasma, without use of preparative ultracentrifuge. Clinical Chemistry 1972; 8: 499-502.

34 Azizi F, Emami H, Salehi P, Ghanbarian A, Mirmiran P, Mirbolooki M, et al. Cardiovascular risk factors in the elderly: the Tehran Lipid and Glucose Study. Journal of Cardiovascular Risk 2003; 10: 65-73.

35 Mirmiran P, Mohammadi F, Allahverdian S, Azizi F. Estimation of energy requirements for adults; Tehran Lipid and Glucose Study. International Journal for Vitamin and Nutrition Research 2003; 73: 193-200.

36 NHLBI Obesity Education Initiative Expert Panel on the Identification, Evaluation and Treatment of Overweight and Obesity in Adults. Clinical guidelines on the identification, evaluation and treatment of overweight and obesity in adults - the evidence report. Obesity Research 1998; 6: 51S-209S.

37 National Cholesterol Education Program (NCEP) Expert Panel on Detection, Evaluation, and Treatment of High Blood Cholesterol in Adults (Adult Treatment Panel III). Third Report of the National Cholesterol Education Program (NCEP) Expert Panel on Detection, Evaluation, and Treatment of High Blood Cholesterol in Adults (Adult Treatment Panel III) final report. Circulation 2002; 106: 3143-421.

38 Expert Committee on the Diagnosis and Classification of Diabetes Mellitus. Report of the Expert Committee on the Diagnosis and Classification of Diabetes Mellitus. Diabetes Care 1997; 20: 1183-97.

39 Joint National Committee on Prevention, Detection, Evaluation and Treatment of High Blood Pressure. The sixth report of the Joint National Committee on prevention, detection, evaluation, and treatment of high blood pressure. Archives of Internal Medicine 1997; 157: 2413-46.

40 Bernstein MA, Tucker KL, Ryan ND, O'Neill EF, Clements $\mathrm{KM}$, Nelson ME, et al. Higher dietary variety is associated with better nutritional status in frail elderly people. Journal of the American Dietetic Association 2002; 102 1096-104.

41 Fernandez E, Negri E, La Vecchia C, Franceschi S. Diet diversity and colorectal cancer. Preventive Medicine 2000; 31: $11-14$.

42 La Vecchia C, Munoz SE, Braga C, Ferandez E, Decarli A. Diet diversity and the risk of colorectal cancer in northern Italy. Cancer Epidemiology, Biomarkers \& Prevention 1996; 5: 433-6.

43 Mirmiran P, Esmaillzadeh A, Azizi F. Dairy consumption and body mass index: an inverse relationship. International Journal of Obesity and Related Metabolic Disorders 2005; 29: $115-21$.

44 Osborne CG, McTyre RB, Dudek J, et al. A prospective study of nutritional factors and hypertension among US men. Circulation 1998; 89: 1475-84.

45 Pereira MA, Jacobs DR Jr, Van Horn L, Slattery ML, Kartashov AI, Ludwig DS. Dairy consumption, obesity, and the insulin resistance syndrome in young adults: the CARDIA Study. Journal of the American Medical Association 2002; 287: 2081-9.

46 McKeown NM, Meigs JB, Liu S, Wilson PW, Jacques PF. Whole-grain intake is favorably associated with metabolic risk factors for type 2 diabetes and cardiovascular diseases in the Framingham Off-spring Study. American Journal of Clinical Nutrition 2002; 76: 390-8.

47 Foote JA, Murphy SP, Wilkens LR, Basiotis PP, Carlson A. Dietary variety increases the probability of nutrient adequacy among adults. Journal of Nutrition 2004; 134: 1779-85.

48 Willett WC. Nutritional Epidemiology, 2nd ed. New York: Oxford University Press, 1998. 